\title{
ATIVIDADES SOCIOEDUCATIVAS SOBRE DESASTRES ASSOCIADOS A DESLIZAMENTOS DE TERRA - ESTUDO DE CASO NUMA COMUNIDADE EM NITERÓI, RJ.
}

\section{Marcos Barreto de Mendonça 1}

RESUMO: A diretriz normalmente adotada para a redução dos desastres associados a deslizamentos de terra no Brasil consiste prioritariamente em executar obras de engenharia para estabilização das encostas. Apesar da contínua e extensa execução desse tipo de ação, alcançando patamares bastante elevados de relação custo/benefício, o problema vem recrudescendo e se disseminando territorialmente. Evidencia-se, assim, uma deficiência dessa diretriz para a redução de desastres. Diante desse quadro, urge avançar em ações preventivas não estruturais para mitigar o problema, entre as quais se destacam atividades socioeducativas sobre o tema. $O$ presente trabalho discorre sobre a pesquisa de uma metodologia educacional para a redução de desastres associados a deslizamentos de terra. São descritas a concepção e aplicação de um conjunto de atividades socioeducativas em uma comunidade de assentamento precário afetada por movimentos de massa no Município de Niterói, RJ. Realizaram-se oficinas de teatro, fotografia, maquete e desenho com os moradores tendo como tema central os desastres associados a deslizamentos. As atividades realizadas possibilitaram a formação de um canal de comunicação sobre os desastres, fazendo permear o tema entre os alunos, os moradores e a equipe técnica envolvida. Entre as atividades realizadas, destacou-se a de elaboração maquetes interativas.

Palavras-chave: Desastres. Deslizamentos. Educação.

1 Engenheiro Civil, D.Sc., Universidade Federal do Rio de Janeiro - Escola Politécnica, mbm@poli.ufrj.br 


\section{INTRODUÇÃO}

Nas últimas décadas tem se verificado um aumento significativo de quantidade e magnitude dos desastres associados a deslizamentos de terra no Brasil em função do contínuo processo de ocupação urbana desordenada de suas encostas. Observa-se, ainda, um aumento da extensão territorial afetada pelos mesmos. Como consequências desses eventos, têm-se mortes, danos sociais e psicológicos relacionados a desabrigados e desalojados e materiais (destruição de moradias, logradouros e de equipamentos públicos).

Feições geológico-geotécnicas atuam como importantes condicionantes dos deslizamentos de terra. Entretanto ações antrópicas resultantes da ocupação desordenada (cortes e aterros para a implantação de moradias e vias de acesso, lançamento de detritos, desmatamentos, redes inadequadas de água e de esgoto, obstrução de cursos d'água naturais) aumentam consideravelmente a susceptibilidade de ocorrência de deslizamentos. Dessas ações resultam a formação de estratos de solo com parâmetros de resistência muito baixos, a sobrecarga do subsolo, taludes mais íngremes e o aumento das poropressões (MENDONÇA E GUERRA, 1997, MENDONÇA et al, 1998, MENDONÇA et al, 2000, CARVALHO et al, 2008). Tendo em vista o esgotamento dos centros urbanos no entorno das capitais brasileiras, esse processo de ocupação desordenada, que antes era limitado às grandes metrópoles, vem sendo registrado em cidades de menor porte.

Estamos ainda longe de viver numa sociedade onde o problema de dificuldade de acesso da população de baixa renda aos serviços sociais básicos como moradia adequada esteja significativamente mitigado. Como consequência, ainda vai persistir por vários anos a pressão por ocupações de áreas impróprias, que, normalmente, se dá de forma desordenada.

Diante desse quadro, a execução de obras de engenharia se mostra bastante limitada como diretriz principal para a redução dos desastres associados a deslizamentos. 
Essas intervenções estruturais atingem patamares muito elevados de relação custo/benefício sem conseguir frear o aumento da frequência e da magnitude dos desastres.

Urge, portanto, avançar em ações preventivas não estruturais, entre as quais se destacam as atividades socioeducativas (CARVALHO, 2010) sobre o tema com os moradores potencialmente afetados de forma incentivá-los a participar da mitigação do problema. Não se deve desqualificar os moradores desses territórios, indivíduos historicamente desfavorecidos no processo de tratamento do problema (VALENCIO, 2009). Muito pelo contrário, devem ser clareadas as ideias de ambas as partes da sociedade, aquela mais favorecida que garante a sobrevivência de forma satisfatória pela força e a constituída pelos mais vulneráveis. Nesse sentido a atividade socioeducativa deve mais do que tentar transmitir conceitos ou orientações técnicas à população, mas promover um diálogo entre os diferentes atores da sociedade envolvidos na temática dos desastres, reduzir a distância social entre os mesmos de forma a promover uma gestão conjunta para a redução dos desastres.

O presente trabalho apresenta a pesquisa sobre a realização de tais atividades a partir de uma experiência numa comunidade de elevada vulnerabilidade socioambiental com histórico de graves desastres associados a deslizamentos no Município de Niterói, região metropolitana do Rio de Janeiro.

\section{DESCRIÇÃO DA ÁREA DE ESTUDO}

A comunidade do Maceió se situa na região central do Município de Niterói, RJ. A área estudada envolve aproximadamente $700.000 \mathrm{~m}^{2}$, apresenta relevo em forma de vale, uma população de aproximadamente de 4.500 habitantes e precária infraestrutura básica. Quanto ao saneamento básico, $71 \%$ dos domićlios têm o abastecimento de água feito através de poço ou nascente e $53 \%$ faz uso da fossa séptica e é frequente o lançamento de lixo e entulho diretamente sobre o terreno. A área está inserida no contexto geomorfológico denominado Maciços Costeiros com seus níveis regulares e pequenos 
vales de fundo aluvial, com as encostas abruptas e pontões rochosos. São predominantes amplitudes topográficas superiores a $300 \mathrm{~m}$ e declividades muito elevadas, com ocorrência de depósitos de colúvio e tálus.

A ocupação do solo, principalmente nas áreas de encostas do bairro se dá de forma bastante desordenada. São facilmente observadas ações de desmatamento, grande quantidade cortes e aterros para a implantação de moradias e vias carroçáveis e de pedestres e lançamentos de esgotos diretamente sobre o terreno.

Como consequência das características geológico geotécnicas naturalmente desfavoráveis e da forma de ocupação do solo, têm-se registrado significativos eventos destrutivos de deslizamentos de terra na área. Destacam-se os eventos de abril de 2010 quando deslizamentos provocaram mortes, perdas materiais e elevados danos sociais devidos a grande quantidade de desabrigados e desalojados (Figura 1).

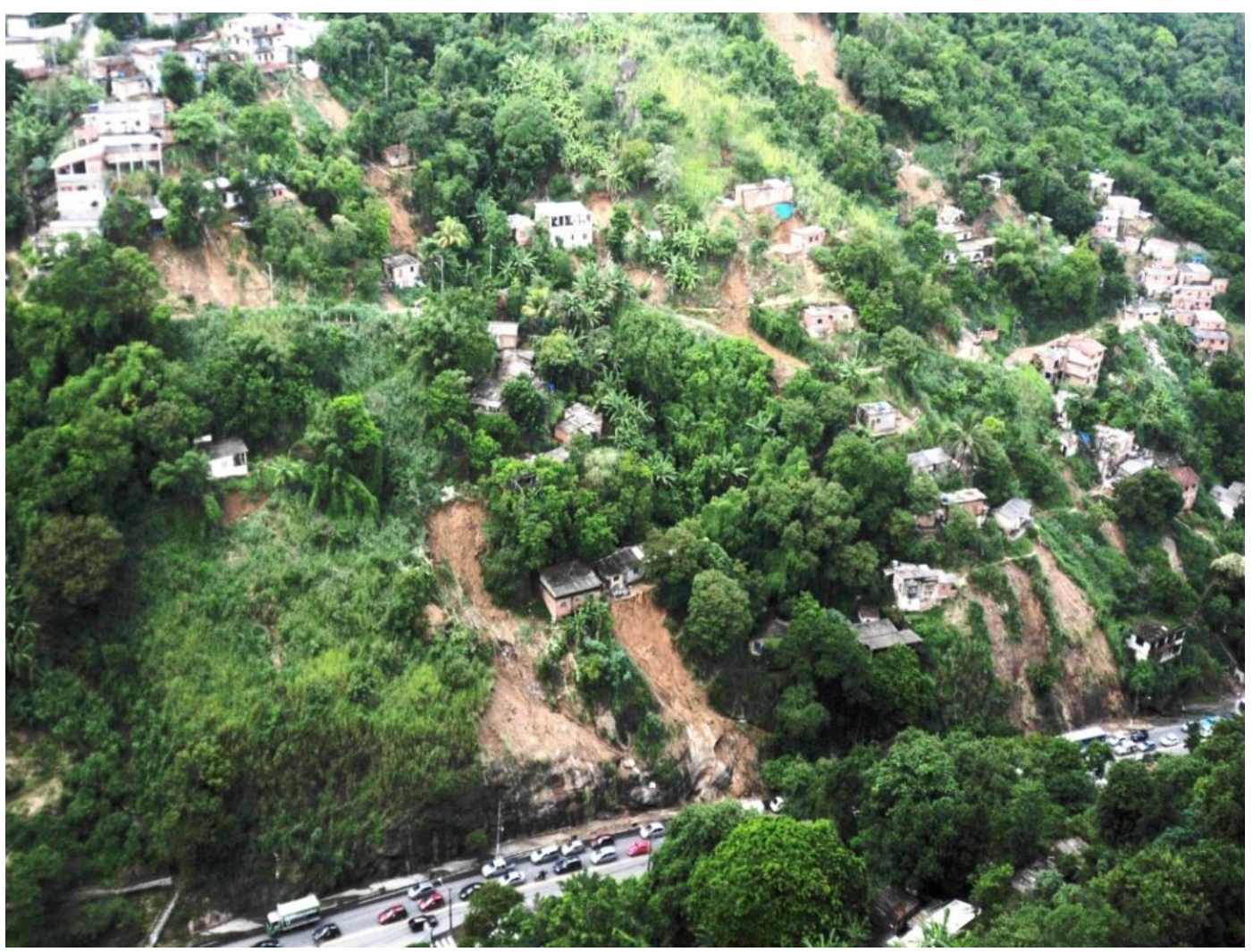

Figura 1 - Uma das encostas na vertente norte da comunidade com várias cicatrizes de deslizamentos ocorridas em abril de 2010. 


\section{ATIVIDADES SOCIOEDUCATIVAS REALIZADAS}

Seguindo os ideais de LUCENA (2008) procurou-se construir novos olhares que incentivassem habilidades da própria comunidade e beneficiassem a organização de diversos atores sociais para a formação de uma cultura de prevenção de desastres. Foi incentivada a formação de grupos de moradores da comunidade para participar de oficinas de atividades de teatro, desenho, fotografia e maquete, sabendo de antemão que teriam como tema central os desastres associados a deslizamentos. Para tal foi importante formar parceria com uma organização não governamental já existente na comunidade, a Oficina do Parque, voltada para atividades artísticas e educativas. Durante as atividades buscou-se um canal de comunicação de forma que as atividades fossem construídas pela associação dos saberes e impressões técnico e popular visando fortalecer a gestão participativa nas ações para a redução de desastres.

Para a concepção inicial e realização das oficinas foram previamente ministradas palestras por engenheiros geotécnicos aos instrutores de cada oficina sobre desastres associados a deslizamentos de forma a transmitir um conhecimento básico sobre o tema. O conteúdo dessas palestras inclui o contexto geral do problema, noções simplificadas sobre mecanismos de deslizamentos, os condicionantes naturais, as ações antrópicas inerentes a ocupação desordenada nocivas a estabilidade das encostas, sinais de iminência de deslizamentos e ações mitigadoras. A partir dessa abordagem técnica inicial houve uma interação entre a equipe técnica e o instrutor de cada oficina para o planejamento específico da mesma.

Nas atividades de teatro, além do objetivo de se ensinar teatro, o trabalho, através de jogos e debates, buscou fazer os alunos mergulharem no cotidiano comum com senso crítico mais aguçado sobre o tema. Foi possível desenvolver um texto a partir das discussões realizadas e, principalmente, com situações vivenciadas pelos próprios alunos na comunidade, transmitindo a visão dos moradores sobre os desastres.

Dentro da oficina de fotografia, foram realizadas atividades em campo na própria 
comunidade, promovendo a interação entre os alunos e engenheiros geotécnicos que apontaram cicatrizes de deslizamentos já ocorridos e suas consequências, as diferentes ações antrópicas que contribuem para aumentar a instabilidade das encostas e sinais de instabilidade iminente. A partir dessas informações e discussões em campo, os alunos fizeram registros fotográficos de seu interesse.

A escolha da atividade de elaboração de maquete como uma das oficinas baseouse na experiência de VALENCIO et al (2009) para desenvolvimento da temática de educação para a redução de desastres relacionados a chuvas com crianças e gestores de Defesa Civil. Segundo esses autores a maquete é um recurso didático no tema de desastres cujos elementos materiais da localidade (como geografia física, topografia e hidrografia) dão base a uma dinâmica de grupo, lúdica e reflexiva junto ao público. No presente trabalho, foi construída uma maquete representando em escala reduzida uma determinada área real da comunidade $(250 \mathrm{~m} \times 250 \mathrm{~m})$, onde foi possível identificar condicionantes geotécnicos e antrópicos desfavoráveis à estabilidade das encostas (Figura 2). Os alunos da oficina construíram os elementos observados na própria comunidade: rios, blocos de rocha, cortes do terreno, casas, ruas, escadarias, lançamento de águas servidas etc. Além disso, foram representados de forma simplificada processos de deslizamento de terra e rolamento de blocos de rocha e suas consequências.
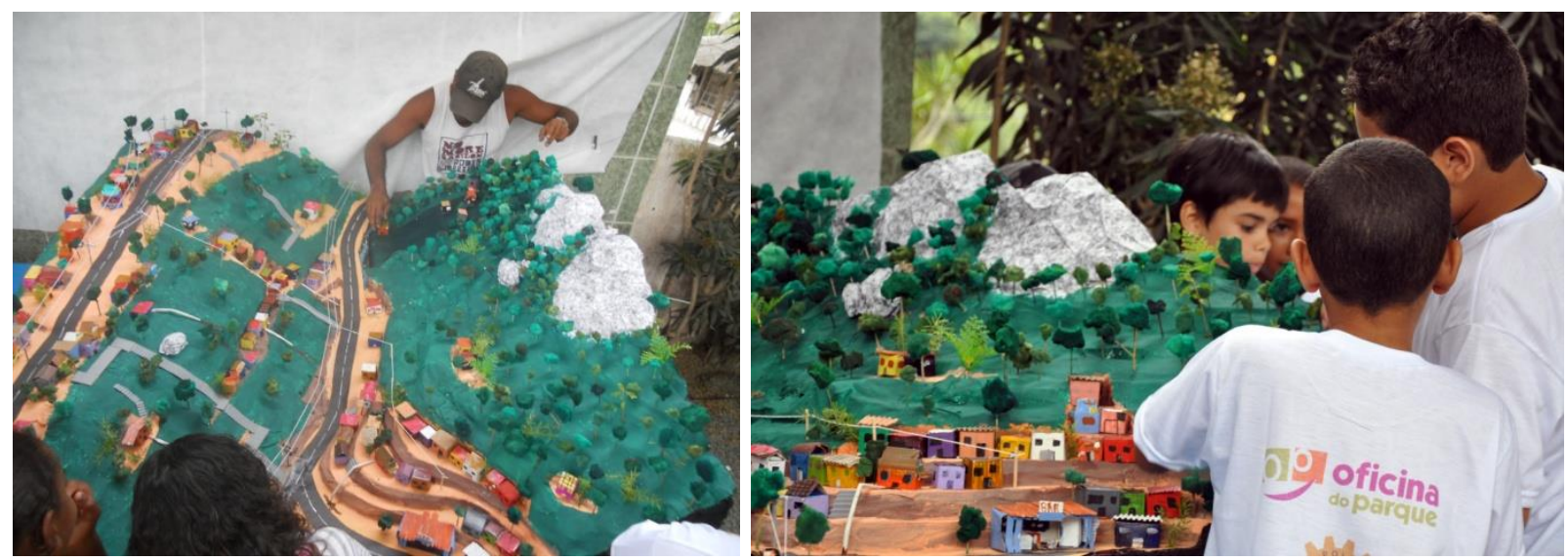

Figura 2 - Fotos da maquete interativa construída durante as atividades da comunidade.

Cartilhas sobre deslizamentos é normalmente o instrumento educativo mais 
utilizado para comunicação de risco entre os agentes públicos e a comunidade, sendo na maioria dos casos, o único empregado. Entretanto, essas cartilhas são elaboradas sob um ponto de vista meramente técnico, não despertando muito interesse dos moradores, que já se encontram bastante distante dos gestores públicos. Visando aproveitar a própria elaboração da cartilha como atividade educativa e uma melhor inserção entre os leitores, os alunos da oficina de desenho foram estimulados a criar de forma visual e sintética uma história em quadrinhos sobre o tema sobre deslizamentos de terra, de forma a tornar o conteúdo mais próximo da realidade dos moradores da comunidade (Figura 3).
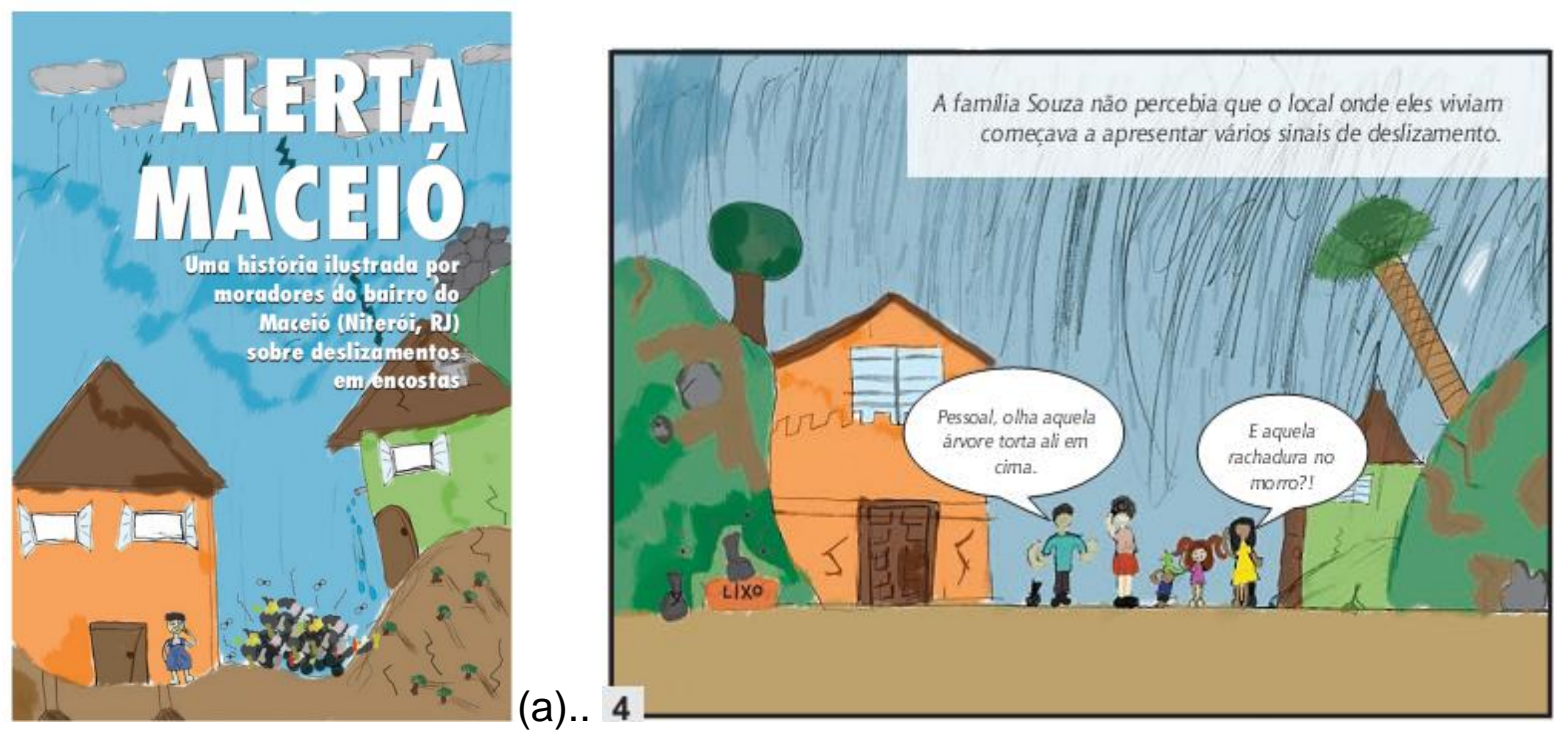

Figura 3 - Capa (a) e uma das páginas internas (b) da história em quadrinhos criada na oficina de desenho.

Ao final das oficinas, que tiveram durações de 2 a 4 meses cada, foi realizado um evento final na comunidade com o objetivo de apresentar os resultados das atividades educativas realizadas, bem como utilizá-los para sensibilizar a comunidade e os gestores públicos convidados sobre o tema. Uma mostra de fotografia, uma maquete interativa, uma peça de teatro, livretos com a história em quadrinhos e um vídeo (disponível na internet: http://www.youtube.com/watch?v=qB_aCziCun8) sobre todas as atividades realizadas durante o projeto foram apresentados durante o evento. 


\section{ANÁLISES DAS ATIVIDADES}

Observou-se que é possível aplicar oficinas de atividades como teatro, maquete, desenho (história em quadrinhos) e fotografia, tendo como tema transversal os desastres associados a deslizamentos de terra. Foi bastante profícua a interação entre a equipe técnica da pesquisa (engenheiros geotécnicos) e os instrutores das atividades artísticas responsáveis pelas oficinas para a concepção das mesmas. Apesar de o tema ser inserido e orientado por uma equipe técnica, os produtos finais foram construídos de forma integrada e interativa pelos próprios moradores. Desta forma, esses produtos expressam a vivência individual e coletiva da comunidade.

Entre as atividades experimentadas durante a pesquisa merece destaque a da construção da maquete interativa, que permitiu agrupar num único instrumento diversos aspectos envolvidos, como condicionantes naturais, ações antrópicas e os sinais de iminência de deslizamentos, bem como as consequências em caso de ocorrência de deslizamentos, promovendo um interesse maior da comunidade durante o evento de apresentação dos resultados.

\section{CONCLUSÕES}

As atividades socioeducativas de teatro, maquete interativa, desenho (cartilha), fotografia e vídeo possibilitaram a formação de um canal de comunicação sobre desastres associados a deslizamentos, fazendo permear o tema entre os alunos, os moradores, instrutores das oficinas e a equipe técnica envolvida. Os resultados das atividades foram, de uma forma geral, produtos da comunicação entre a comunidade afetada e técnicos. Neste sentido, a atividade de construção maquete interativa se destacou pela facilidade de comunicação e por permitir uma melhor integração entre os atores.

Uma marca das atividades empregadas nesta pesquisa em relação a ações educativas tradicionais com o mesmo objetivo é que as primeiras foram construídas com 
a participação dos moradores e não impostas por agentes públicos que vivem em outra realidade socioambiental. Praticou-se, assim, uma "gestão de proximidade" (LUCENA, 2008), onde todos se sentem agentes da transformação e da mudança com vistas à redução dos desastres na comunidade em que residem. Entende-se que com a interação dos sujeitos envolvidos na construção cidadã (agentes públicos, técnicos e moradores) deve ocorrer um processo de maturação onde os mesmos passam a decidir conjuntamente as suas prioridades.

O eixo da proposta está centrado, sobretudo, na sensibilização e formação de agentes multiplicadores focando-se na importância da percepção dos riscos e na comunicação permanente que possam elevar o grau de preocupação do jovem quanto a sua realidade e a partir disso, construir perspectivas de uma comunidade mais segura.

\section{AGRADECIMENTOS}

Os autores agradecem à Fundação Carlos Chagas Filho de Amparo a Pesquisa do Estado do Rio de Janeiro (FAPERJ) pelo apoio a atividades desenvolvidas neste trabalho.

\section{REFERÊNCIAS}

CARVALHO, JOSÉ CAMAPUM. Gestão de riscos em encostas: implicações geotécnicas da ocupação e uso do solo e sua relação com a educação ambiental, com as limitações das normas técnicas e com a falta de efetividade das normas administrativas e jurídicas. Anais XV Congresso Brasileiro de Mecânica dos Solos e Engenharia Geotécnica. Gramado, ABMS, v. 1. p. 327-334, 2010.

LUCENA, Rejane. Mobilização social para a redução de vulnerabilidades. Gestão e Mapeamento de Riscos Socioambientais. Ministério das Cidades / UFPE, 2008.

MENDONÇA, Marcos Barreto; GUERRA, Antônio Teixeira. A Problemática dos Processos Geodinâmicos frente ao Ocupação Encostas, Anais 2nd Panamerican Symposium on Landslides, Rio de Janeiro, vol. 2, pp.935-940, 1997.

MENDONÇA, Marcos Barreto et al. A Preservação das Encostas por meio da Urbanização de Favelas no Município do Rio de Janeiro. Anais XI Congresso Brasileiro de Me- 
cânica dos Solos e Engenharia Geotécnica. Brasília, vol. I, pp. 457-463, 1998.

MENDONÇA, Marcos Barreto et al. Experiences on Diagnosis and Treatment of UrbanSlopes in Rio de Janeiro, Brazil. Proc. 5th International Symposium on Environmental Geotechnology and Global Sustainable Development, Belo Horizonte, 2000.

VALENCIO, NORMA et al. Maquetes Interativas: fundamentos teóricos, metodológicos e experiências de aplicação. Sociologia dos Desastres- Construção, Interfaces e Perspectivas no Brasil. São Carlos, Rima Editora, 2009.

VALENCIO, NORMA. Da morte da Quimera à procura de Pégaso: a importância da interpretação sociológica na análise do fenômeno denominado desastre. Sociologia dos Desastres- Construção, Interfaces e Perspectivas no Brasil. São Carlos, Rima Editora, 2009. 